American J. of Engineering and Applied Sciences 4 (4): 531-539, 2011

ISSN 1941-7020

(C) 2014 Aleksic and Lovric, This open access article is distributed under a Creative Commons Attribution

(CC-BY) 3.0 license

\title{
Energy Consumption and Environmental Implications of Wired Access Networks
}

\author{
Slavisa Aleksic and Ana Lovric \\ Institute of Telecommunications, \\ Faculty of Electrical Engineering and Information Technology, \\ Vienna University of Technology, Favoritenstr 9-11/389, Vienna, Austria
}

\begin{abstract}
Problem statement: Wired broadband Internet access can be realized using various technologies, configurations and protocols. It is widely deployed and able to provide both high data rates and high reliability. These features are of strong importance for many advanced applications. Since the number of broadband subscribers worldwide grows exponentially, the power efficiency of access networks becomes increasingly important. Approach: The aim of this study is to study power consumption of different wired broadband access technologies including both those already widely used and those which are state-of-the-art, but not yet widely deployed. For this purpose, we developed a model for evaluating energy efficiency of wired access networks. The model is presented and applied to study energy efficiency of various access networks such as Hybrid Fiber Coax (HFC), Digital Subscriber Line (DSL), 1 and $10 \mathrm{Gbit} / \mathrm{s}$ point-to-point ethernet and Passive Optical Networks (1G-PON and 10G-PON). The metric for energy efficiency we used in this study is energy consumed per bit transmitted. Results: Results of the comparative study on energy efficiency of different access networks are shown and discussed. Additionally, we estimated environmental implications of different access options by means of reductions in Green House Gas (GHG) emissions caused by the electricity consumption of access network infrastructure. Conclusion: We found out that high-speed optical access technologies providing up to $10 \mathrm{Gbit} / \mathrm{s}$ per user have the potential to achieve the highest energy efficiency when assuming future broadband Internet access and broad use of advanced services and applications. However, for lower access data rates, 1G-PONs are the most energy efficient access options. Coper-based access technologies provide generally lower energy efficiency than the fiber based solutions. For transferring a large amount of data and when network equipment is switched off during its inactivity times, optical access technologies have the highest potential to reduce GHG emissions caused by the electricity consumption of access network infrastructure.
\end{abstract}

Key words: Energy efficiency, communication networks, wired access networks, greenhouse gas emissions

\section{INTRODUCTION}

Nowadays, the majority of broadband access subscribers have either a wired access over telephone lines, in most cases a version of Digital Subscriber Line (DSL), or a wireless access such as WiMAX, WiFi, GSM or UMTS. Another widely deployed access technology is the Hybrid Fiber Coax (HFC) solution that uses fiber running from the central office of a network provider to a Remote Node (RN) and coaxial cable from the node to subscribers. An adequate converter in the RN adapts the signal from one to the other transmission medium. HFC systems reuse the widely deployed Cable TV (CATV) network infrastructure.

Recently, there have been a large number of projects concentrating on fiber-based optical access networks for broadband transmission of data generally named Fiber-ToThe-x (FTTx). There are different options for FTTx depending on how near to the subscriber the fiber reaches. A typical example is the Fiber-To-The-Home (FTTH), which means that optical signal reaches the end subscriber's equipment situated in the subscriber home.

Corresponding Author: Slaviaa Aleksic, Institute of Telecommunications, Faculty of Electrical Engineering and Information Technology, Vienna University of Technology, Favoritenstr. 9-11/389, Vienna, Austria Tel: +43 1 5880138831 Fax: +43158801938831 
Other examples are Fiber-To-The-Building (FTTB), Fiber-To-The-Curb (FTTC), Fiber-To-The-Node (FTTN). When looking at the topology of the access network, it can be either ring or tree or a combination of those two topologies. Additionally, interconnections can be based on unidirectional or bidirectional fibers in a Point-to-Point ( $\mathrm{P}$ t-P) or Point-to-Multipoint (P-t-MP) arrangement.

The number of broadband subscribers worldwide has grown exponentially during the last decade. Since recently, also the number of FTTH connections has been remarkably growing. For example, in the United States, the annual growth rate was above $100 \%$ between 2002 and 2008 (RVA Market Research and Consulting, 2011). While still relatively strong, FTTH growth has slowed somewhat since 2008. There are currently about 20.9 million homes in North America where a fiber connection is technically available and approximately 7 million homes actually connected with lit fiber (RVA Market Research and Consulting, 2011). In Japan, the number of FTTH connections has exceeded that of ADSL in January 2007 (Suzuki, 2008). In Asia, there are currently around $78 \%$ of the world's FTTH subscribers. In the first half of 2009, the growth rates in China and Taiwan were $167 \%$ and $25 \%$, respectively (IDATE Consulting and Research, 2010). More subscribers and higher data rates per subscriber mean higher total power consumption of the entire access network infrastructure. However, different Internet access options provide different data rate per subscriber and consume more or less power. Although there has been a lot of research effort put in the investigation of technological aspects of access networks, there are only a few works concentrating on power consumption issues (Baliga et al., 2008; Lovric and Aleksic, 2010; Aleksic and Lovric, 2010). In general, energy efficiency of global communication networks has gained a lot of interest from research community (Aleksic, 2011). Currently, the most of the electricity consumed by the network infrastructure is due to access networks.

This study aims to evaluate power consumption of different wired access technologies and to compare them by means of power efficiency. The study is organized as follows: The next section describes the considered technologies and the model used to evaluate their power consumption. The obtained results are shown in the "Results" The "Discussion" addresses possible environmental impact of the considered access technolgoes. Finally, the last summarizes and concludes the study.

\section{MATERIALS AND METHODS}

Considered access technologies: The access network technologies that we took into consideration in our study are depicted in Fig. 1. First we considered the conventional and very widely deployed copper-based access technologies such as xDSL (Starr et al., 2003) and HFC (Large and Farmer, 2009). Here, we chose two options for xDSL access that are currently being deployed, namely ADSL2+ (ITU-T, 2009) and VDSL2 (ITU-T, 2006), because they are the most recent DSL specifications that are able to provide high data rates and to support current triple play services. Hybrid Fiber Coax (HFC) is considered because it is widely used and also supports high data rates and triple-play services within its latest version DOCSIS 3.0 (CableLabs, 2007-2010). For both xDSL and HFC we assume the Fiber-To-The-Node (FTTN) scenario, in which the DSL Access Multiplexer (DSLAM) is situated in a remote node that is connected via an optical fiber to the Central Office (CO) equipment, while DSL is then applicable on copper wires reaching from the remote node's DSLAM to the Customer Premises Equipment (CPE).

For optical access we considered two different topologies, namely Point-to-Point (P-t-P) and Point-toMultipoint (P-t-MP). P-t-P systems are implemented using direct connections between CPEs and COs through 1 Gbit/s or $10 \mathrm{Gbit} / \mathrm{s}$ Ethernet links. In the case of P-tMP systems, we considered Gigabit Passive Optical Network (GPON) (ITUT-T, 2008), Ethernet PON (1G-EPON) (IEEE P802.3ah, 2008) and $10 \mathrm{Gbit} / \mathrm{s}$ Ethernet PON (10G-EPON) IEEE 802.3av 10GEPON Task Force. The considered optical access technologies are referred to as Fiber-To-The-Home (FTTH) networks (ITU-T, 2009).

Access network model: Different access solutions provide different data rates per subscriber and allow unequal distances between the $\mathrm{CO}$ and end subscribers. Additionally, typical configurations vary from case to case. Therefore, it is not easy to fairly compare different access technologies with each other.

In our study, we decided to look at maximum achievable data rates for each technology and to neglect differences in maximum reach, i.e., not to take into account the effect of reducing the data rate with increasing the transmission distance. Since both xDSL and HFC are assumed to be implemented in the FTTN configuration, we assume that copper cables are not longer than few hundreds of meters. In this case, both xDLS and HFC systems are capable of providing the highest specified data rates over such short copper links. Thus, the assumption of neglecting the data rate limitation caused by increase of transmission distance is reasonable in this case. 


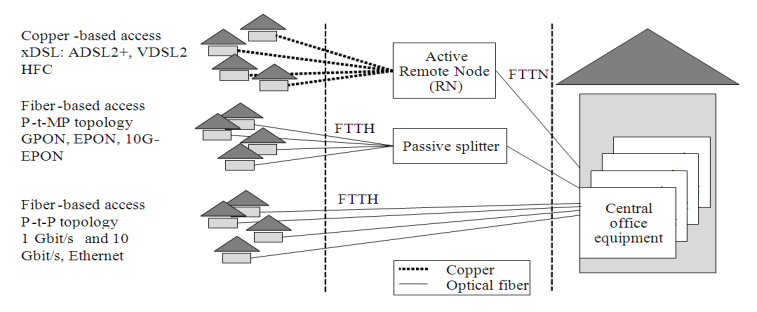

Fig. 1: Considered access network technologies

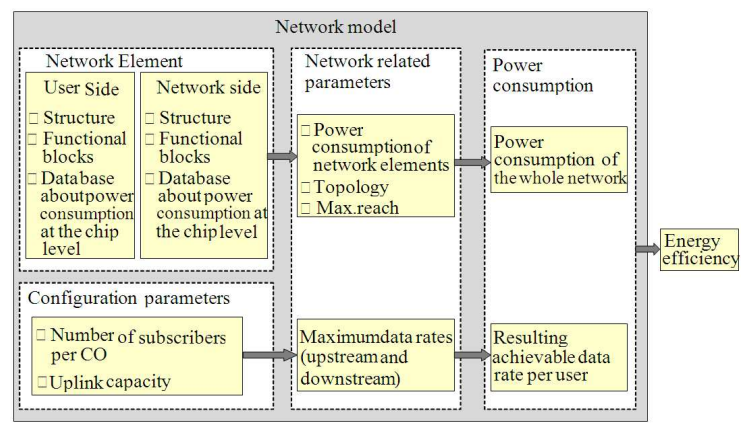

Fig. 2: Schematic depiction of the network model

Please note that an all-copper solution, i.e. when electrical signals are transmitted over copper cables directly from central office to user premises, would result in significantly reduced data rates for long distances in case of XDSL and consequently in a much lower energy efficiency of copper-based access technologies. The main parameters of different FTTN and FTTH options as specified in respective standards are listed in Table 1.

Table 1: Main parameters of the considered access networks (Starr $e t$ al., 2003; Large and Farmer, 2009; ITU-T, 2009; ITU-T, 2006; CableLabs, 2007-2010; ITUT-T, 2008; IEEE P802.3ah, 2008)

\begin{tabular}{|c|c|c|c|c|}
\hline \multirow[t]{2}{*}{$\begin{array}{l}\text { Number of } \\
\text { channels }\end{array}$} & \multicolumn{2}{|c|}{$\begin{array}{l}\text { Maximum } \\
\text { data rates }\end{array}$} & \multirow{2}{*}{$\begin{array}{l}\text { Max. } \\
\text { [Mbit/sec] }\end{array}$} & \multirow{2}{*}{$\begin{array}{l}\text { reach } \\
{[\mathrm{km}]}\end{array}$} \\
\hline & US & $\begin{array}{l}\text { DS US } \\
{[\mathrm{Mbit} / \mathrm{sec}]}\end{array}$ & & \\
\hline HFC DOCSIS 3.0 & 4 & 152 & 108 & N/A \\
\hline ADSL2+ & N/A & $24 *$ & $1.4^{*}$ & 5.5 \\
\hline VDSL2 asymmetric & N/A & $100 *$ & $50 *$ & 2 \\
\hline VDSL2 symmetric & N/A & $100 *$ & $100 *$ & 2 \\
\hline $\begin{array}{l}\text { Splitting } \\
\text { ratio }\end{array}$ & & $\begin{array}{l}\text { Maximum } \\
\text { data rates }\end{array}$ & & $\begin{array}{l}\text { Max. } \\
\text { reach }\end{array}$ \\
\hline FTTH & & $\begin{array}{l}\text { DS US } \\
{[\mathrm{Mbit} / \mathrm{sec}]}\end{array}$ & [Mbit/sec] & {$[\mathrm{km}]$} \\
\hline 1G-EPON & $1: 32$ & 1000 & 1,000 & 20 \\
\hline GPON & $1: 32$ & 2,300 & 1,000 & 20 \\
\hline 10G-EPON symmetric & $1: 32$ & 10,000 & 10,000 & 20 \\
\hline 10G-EPON asymmetric & $1: 32$ & 10,000 & 1,000 & 20 \\
\hline $1 \mathrm{G}$ Ethernet (P-t-P) & N/A & 1,000 & 1,000 & 20 \\
\hline 10G Ethernet (P-t-P) & N/A & 10,000 & 10,000 & 40 \\
\hline
\end{tabular}

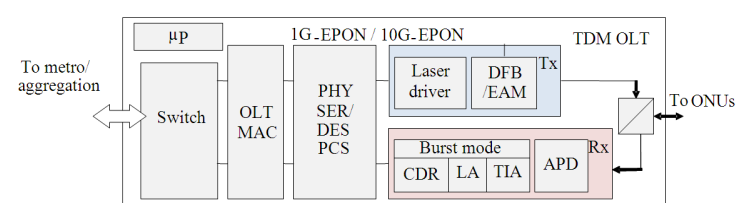

(a)

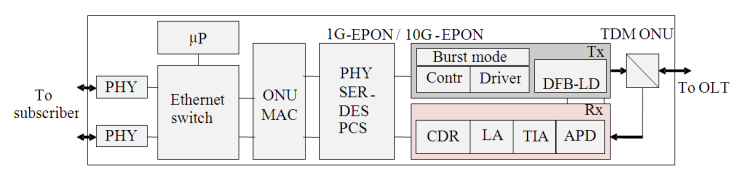

(b)

Fig. 3: Generic structures of 1G-EPON and 10GEPON: (a) Optical Line Terminal (OLT) and (b) Optical Network Unit (ONU)

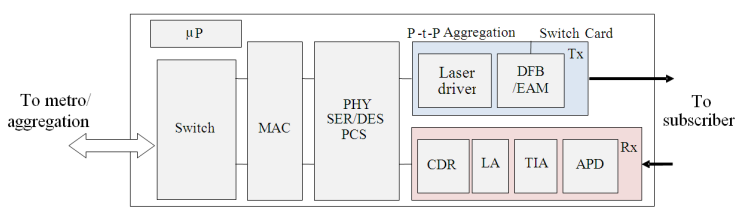

(a)

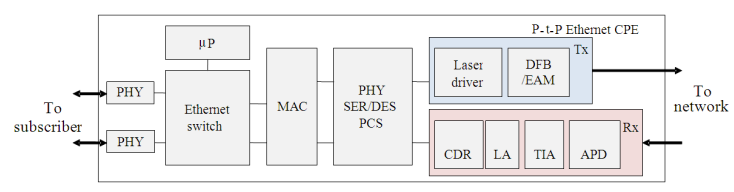

(b)

Fig. 4: Generic structures of P-t-P $1 \mathrm{G}$ and 10G Ethernet (a) aggregation switch and (b) Customer Premises Equipment (CPE)

The entire network model includes several modules as shown in Fig. 2. The network elements are modeled at the chip level. That means we fist specified a generic structure for both network-side and subscriber-side elements and then calculated their total power consumption by summing up values for consumption of individual functional blocks, i.e., Integrated Circuits (ICs). For instance, the generic structures of $1 \mathrm{G}$ and 10G EPON elements are shown in Fig. 3 and those of $1 \mathrm{G}$ and 10G P-t-P Ethernet are depicted in Fig. 4. The power consumption of a functional block is obtained by averaging the consumption values of a number of components currently available on the market. In order to validate our model of network elements, the obtained values for their total power consumption are compared to those given in technical specifications of some commercially available systems. In case of the widely deployed HFC and xDSL systems, we created a data 
Am. J. Engg. \& Applied Sci., 4 (4): 531-539, 2011

base of network elements, i.e., Cable Modem Termination Systems (CMTSs), DSLAMs and DSL/HFC modems and calculated mean values that we used for the calculation of power efficiency. The calculated values of total power consumption per network element are shown in Table 2, which also contains maximum achievable net line data rates for each technology, i.e., the data rates excluding the line coding overheads. The values of transceivers' power consumption are typical consumption values for transmission distances of up to $10 \mathrm{~km}$. The same reach is assumed for both FTTH and FTTN access options. Other parameters that define our network model can be described as configuration and network-related parameters. Configuration parameters include number of subscribers per central office and the uplink capacity of the entral office $\left(\mathrm{C}_{\mathrm{U}}\right)$. Network-related parameters are firstly the network-specific topology and maximum reach as well as the power consumption of the corresponding network elements and secondly the maximum upstream and downstream data rates per subscriber that are directly influenced by the applied network configuration and its parameters. The combination of the mentioned parameters and their values represent the input to the model used for calculation of energy efficiency. The output of the model is the energy efficiency obtained by combining the power consumption of the whole network and the resulting achievable data rates per subscriber.

Thus, the resulting energy efficiency, i.e., the energy needed to transfer a bit of information through the access network, is expressed in Joule per subscriber per bit (W/bit/s $\equiv \mathrm{J} / \mathrm{bit})$.

The considered data rates for different technologies are net line data rates excluding coding overhead. For instance in the case of P-t-P 1G Ethernet, we assume 1 Gbit/s (w/o the overhead associated with the 8B/10B coding) in both directions, unless it is limited by the uplink of the aggregation switch in the CO. In other words, both protocol inefficiency and subscriber behavior are not taken into account because it would make the comparison much more complex.

The active users in a passive optical network equally share the available bandwidth. For both FTTN and FTTH P-t-P networks, we assume that all users can achieve the maximum data rate unless there is another limiting factor. The data rate per user in this case is only limited by the maximum capacity of the aggregation switch to which they are connected and by the maximum uplink capacity of the corresponding CO.
Table 2: Obtained values of power consumption for different access network elements

\begin{tabular}{|c|c|c|c|c|c|}
\hline \multicolumn{2}{|c|}{$\begin{array}{l}\text { Max. number Max. data } \\
\text { of ports }\end{array}$} & a & & \multicolumn{2}{|l|}{$\begin{array}{l}\text { Power } \\
\text { consumption }\end{array}$} \\
\hline $\begin{array}{l}\text { Network } \\
\text { Element }\end{array}$ & DS & US & $\begin{array}{l}\mathrm{DS} \\
{[\mathrm{G} \mathrm{bit} / \mathrm{sec}]}\end{array}$ & $\begin{array}{l}\text { US } \\
{[\mathrm{G} \mathrm{bit} / \mathrm{sec}]}\end{array}$ & {$[\mathrm{W}]$} \\
\hline HFC CMTS & 72 & 1.0 & 10.000 & 10.0000 & 1,350 \\
\hline $\begin{array}{l}\text { HFC DOCSIS } \\
\text { 3.0 Modem }\end{array}$ & 1 & 1.0 & 0.152 & 0.1080 & 9 \\
\hline $\begin{array}{l}\text { ADSL2+ } \\
\text { DSLAM }\end{array}$ & 48 & 1 & 1.000 & 1.0000 & 83 \\
\hline ADSL2+ modem & 1 & 1.0 & 0.024 & 0.0014 & 8 \\
\hline $\begin{array}{l}\text { VDSL2 } \\
\text { DSLAM }\end{array}$ & 16 & 2.0 & 2.000 & 2.0000 & 64 \\
\hline VDSL modem & 1 & 1.0 & 0.100 & 0.1000 & 7 \\
\hline 1G-EPONOLT & $32 \times 4 *$ & 1.0 & 4.000 & 10.0000 & 45 \\
\hline 1G-EPON ONU & 1 & 1.0 & 1.000 & 1.0000 & 13 \\
\hline GPON B+OLT & $32 \times 4 *$ & 1.0 & 10.000 & 10.0000 & 47 \\
\hline $\begin{array}{l}\text { GPON B+ONU1 } \\
\text { 10G-EPON }\end{array}$ & 1 & 2.3 & 1.000 & 17.0000 & \\
\hline OLT $10 \mathrm{G}$ & $32 \times 4 *$ & 4.0 & 40.000 & 40.0000 & 111 \\
\hline EPON ONU & 1 & 1.0 & 10.000 & 10.0000 & 29 \\
\hline $\begin{array}{l}\text { 1G Ethernet } \\
\text { aggregation } \\
\text { switch (P-t-P) }\end{array}$ & 24 & 2.0 & 20.000 & 20.0000 & 114 \\
\hline $\begin{array}{l}1 \mathrm{G} \text { Ethernet } \\
\text { CPE (P-t-P) }\end{array}$ & 1 & 1.0 & 1.000 & 1.0000 & 7 \\
\hline $\begin{array}{l}10 \text { G Ethernet } \\
\text { aggregation } \\
\text { switch (P-t-P) }\end{array}$ & 12 & 1.0 & 10.000 & 120.0000 & 121 \\
\hline $\begin{array}{l}10 \mathrm{G} \text { Ethernet } \\
\text { CPE (P-t-P) }\end{array}$ & 1 & 1.0 & 10.000 & 10.0000 & 28 \\
\hline
\end{tabular}

Due to the fact that users of passive optical networks connected to the same OLT have to share both Up Stream (US) and Down Stream (DS) data rates, they cannot reach the maximum data rates listed in Table 2 unless there is only one user per OLT. While in P-t-P networks both broadcast and multicast traffic have to be multiplied and transmitted to the users in parallel over different links, PONs can naturally support broadcast and multicast services by sending only a single data stream to all users. This property of PON options is addressed by introducing the broadcast factor, $B$, which represents the percentage of the downstream data rate used for broadcast services. Thus, the total bidirectional data rate of a single user in a PON, $R_{U}$, can be calculated by considering the following three cases.

Case 1: The total bandwidth consumed by all active users is below the given limit, $\mathrm{C}_{\mathrm{U}}$, which is the maximum bidirectional uplink capacity of the central office switch, i.e., when $\mathrm{C}_{U}>\mathrm{N}_{\mathrm{OLT}}\left(\mathrm{r}_{\mathrm{US}}+\mathrm{r}_{\mathrm{DS}}\right)$, where $\mathrm{r}_{U S}$ and $r_{D S}$ represent the maximum upstream and downstream data rates, respectively. $\mathrm{N}_{\text {OLT }}$ is the total number of optical line terminals in the CO. In this case, all users can be provided with the maximum data rates 
in both upstream and downstream directions and the total bidirectional data rate of a single user can be calculated using Eq. 1:

$\mathrm{R}_{\mathrm{u}}^{1}=\mathrm{r}_{\mathrm{DS}} \cdot \mathrm{B}+\left[\mathrm{r}_{\mathrm{DS}}(1-\mathrm{B})+\mathrm{r}_{\mathrm{US}}\right] \cdot \frac{\mathrm{N}_{\mathrm{OLT}}}{\mathrm{N}_{\mathrm{user}}}$

where, $\mathrm{N}_{\text {user }}$ is the total number of active users connected to the $\mathrm{CO}$.

Case 2: The second condition reflects the case in which the bandwidth limitation is reached, but there is still no effect on the broadcast traffic, i.e., when $\mathrm{C}_{\mathrm{U}}<\mathrm{C}_{\mathrm{U}}<$ $\mathrm{N}_{\mathrm{OLT}}\left(\mathrm{r}_{\mathrm{US}}+\mathrm{r}_{\mathrm{DS}}\right)$ but $\left(\mathrm{C}_{\mathrm{U}}-\mathrm{N}_{\mathrm{OLT}} \cdot \mathrm{r}_{\mathrm{US}, \mathrm{L}}\right) / \mathrm{N}_{\mathrm{OLT}}>\mathrm{r}_{\mathrm{DS}} \cdot \mathrm{B}$, where $r_{U S, L}$ represents the reduced upstream data rate due to the limitation of the uplink $\left(\mathrm{C}_{\mathrm{U}}\right)$. In this case, both downstream and upstream data rates are reduced, but not as much to affect delivering of broadcast services. The data rate per user can be then calculated by the following Eq. 2 formula:

$R_{u}^{2}=r_{D S} \cdot B+\left(r_{D S, L}-r_{D S} \cdot B+r_{U S, L}\right) \cdot \frac{N_{O L T}}{N_{u s e r}}$,

where, $r_{D S, L}$ is the reduced downstream data rate due to the limitation of the uplink.

Case 3: Finally, the third case refers to a strong reduction in the available bandwidth per user due to the uplink limitation, where not only the best-effort but also the prioritized broadcast traffic is throttled. In this case we have $\mathrm{C}_{\mathrm{U}}<\mathrm{N}_{\text {OLT }}\left(\mathrm{r}_{\mathrm{US}}+\mathrm{r}_{\mathrm{DS}}\right)$ and $\left(\mathrm{C}_{\mathrm{U}}-\mathrm{N}_{\text {OLT }} \cdot \mathrm{r}_{\mathrm{US}, \mathrm{L}}\right) / \mathrm{N}_{\text {OLT }}<$ $\mathrm{r}_{\mathrm{DS}} \cdot \mathrm{B}$ and the achievable data rate per user is then Eq. 3:

$R_{u}^{3}=r_{D S, L}+r_{U S, L} \cdot \frac{N_{O L T}}{N_{u s e r}}$

The reduced upstream and downstream data rates are given by Eq.4-6:

$$
\begin{aligned}
& \mathrm{r}_{\mathrm{DS}, \mathrm{L}}=\frac{\mathrm{C}_{\mathrm{U}}}{\mathrm{N}_{\mathrm{OLT}} \cdot\left(\frac{\mathrm{r}_{\mathrm{US}}}{\mathrm{r}_{\mathrm{DS}}}+1\right)}, \\
& \mathrm{r}_{\mathrm{US}, \mathrm{L}}=\frac{\mathrm{C}_{\mathrm{U}}}{\mathrm{N}_{\mathrm{OLT}}}-\mathrm{r}_{\mathrm{DS}, \mathrm{L}},
\end{aligned}
$$

and:

$$
\frac{C_{U}}{N_{\text {OLT }}}=r_{D S, L}+r_{U S, L}
$$

\section{RESULTS}

Energy efficiency of access networks: Energy efficiency of the access technologies briefly discussed "Materials and Methods" is estimated by considering the following two scenarios. The first one does not include any limitation of the uplink in central offices of network providers. It gives the theoretically highest possible efficiency that can be achieved by each technology. The second scenario is a more realistic one because it foresees that there are limited resources available in the central office, i.e., in the metropolitan area network. For this case we assume a 10-hop, 80-channel WDM metro ring providing $40 \mathrm{Gbit} / \mathrm{s}$ wavelength channel and 1,000 subscribers per CO. The total capacity of the ring is then $40 \mathrm{Gbit} / \mathrm{s} \times 80$ wavelengths $=3.2 \mathrm{Tbit} / \mathrm{s}$. Thus, if the available capacity is equally divided among all nodes, than each $\mathrm{CO}$ would have a maximum uplink capacity of $320 \mathrm{Gbit} / \mathrm{s}$.

The values of power consumption for both the concentration equipment located in central offices of network providers and the customer premises equipment are summarized in Table 2 . The values are obtained by defining generic structures of network elements and calculating the typical power consumption per element. The power consumption values for each functional block, i.e., for a component or a chip within a network element, are obtained by averaging the typical power consumption values of a number of components currently available on the market. The access network is populated step by step. That means if there is only one subscriber connected to a $\mathrm{CO}$, then only one concentration element is used. As soon as the number of subscribers per $\mathrm{CO}$ exceeds the number of lines that one concentration element can provide, a new concentration element is added.

Figure 5 shows results of power efficiency for the considered access technologies when the number of subscribers connected to a $\mathrm{CO}$ increases form 1 to 1,000. The results are obtained by using the model presented and by setting the broadcast factor B to $100 \%$. Hence, data transmitted in the downstream direction is broadcasted to all users within the corresponding PON, while the upstream capacity is equally shared among the active users. The curves presented in Fig. 5a and $5 \mathrm{~b}$ are obtained without considering any bandwidth limitation in the CO. It is evident that the fiber-to-the-node options (Fig. 5a) are generally less energy efficient than the fiber-to-thehome networks (Fig. 5b). 


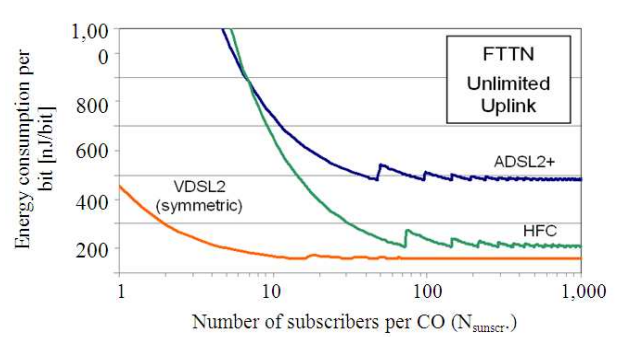

(a)

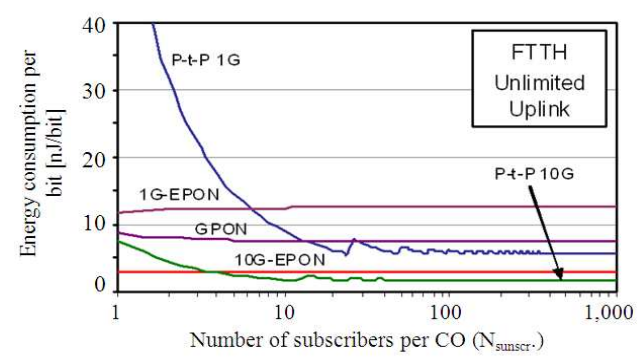

(b)

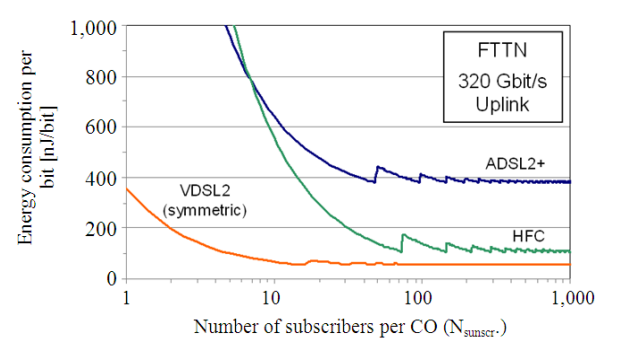

(c)

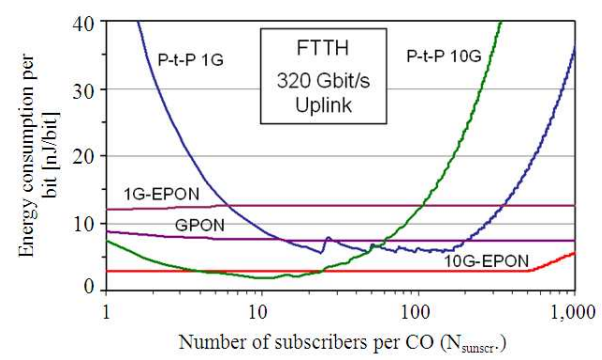

(d)

Fig. 5: Power efficiency of (a) FTTN and (b) FTTH access options when assuming an unlimited available capacity in $\mathrm{CO}$ as well as (c) FTTN and (d) FTTH when the available capacity of the $\mathrm{CO}$ uplink is limited to $320 \mathrm{Gbit} / \mathrm{s}$

Because FTTN configurations provide a relatively low data rate per subscriber and a large number of subscribers per concentration element, they tend to be very energy inefficient for a small number of subscribers. When the number of subscribers increases and the capacity of the concentration element (CMTS or DSLAM) is effectively utilized, they become more efficient, but still for an order of magnitude less efficient than the optical access options. In our study, the most efficient copper-based technology was VDSL2 with $56 \mathrm{~W} / \mathrm{Gbit} / \mathrm{s}$ per subscriber for the case of 1,000 subscribers per CO. The FTTH options show generally better efficiency than the FTTN ones (Fig. 5b).

Please note that for FTTH technologies we considered symmetric options only, i.e., maximum data rates in both upstream and downstream directions are assumed to be equal. If only few customers are connected to a $\mathrm{CO}$, then the P-t-P $1 \mathrm{G}$ Ethernet shows the lowest efficiency among all the considered optical access network options. This is because the aggregation switch consumes more power than a PON port and the advantage of a dedicated connection to each subscriber does not play a significant role because PON subscribers also achieve a relatively large data rate for a low number of subscribers. The equipment providing $10 \mathrm{Gbit} / \mathrm{s}$ also consumes large power, but it provides 10 -times larger data rate than the $1 \mathrm{Gbit} / \mathrm{s}$ one. When the number of active users increases above few tens, then P-t-P $1 \mathrm{G}$ option becomes more efficient than $1 \mathrm{G}$ EPON and GPON. In this theoretical scenario without any bandwidth limitation, $10 \mathrm{Gibt} / \mathrm{s}$ systems would provide the highest power efficiency. Thus, if we would have a huge capacity within the metropolitan area such that very high speed access at $10 \mathrm{Gbit} / \mathrm{s}$ could be provided to 1,000 customers at the same time, then the most power efficient option would be P-t-P $10 \mathrm{Gbit} / \mathrm{s}$ Ethernet.

In order to study a more realistic case, we limited the uplink capacity per $\mathrm{CO}$ to $320 \mathrm{Gbit} / \mathrm{s}$ The results for this limited capacity case are shown in Fig. 5c and 5d. The capacity limitation has no impact on the FTTN options because they can hardly exceed the maximum capacity of $320 \mathrm{Gbit} / \mathrm{s}$ per CO with 1,000 subscribers. Therefore, the results obtained for the theoretical unlimited case are also valid for the limited case and the curves shown in Fig. 5c do not differ to those presented in Fig. 5a. On the contrary, the optical point-to-point access technologies are strongly influenced by this limitation, especially those providing $10 \mathrm{Gbit} / \mathrm{s}$ access. P-t-P 10G Ethernet exceeds this limit already for few tens of subscribers. Hence, it becomes the most inefficient one when the number of subscribers per $\mathrm{CO}$ grows above 100. This effect can be explained as follows. A growing number of subscribers imply an increase in required number of network terminals, i.e., a higher total power consumption. At the same time, the data rate per subscriber decreases due to the bandwidth limitation in the $\mathrm{CO}$, i.e., subscribers cannot exploit their maximum data rates anymore. Consequently, an increase of energy per bit, or equivalently a decrease of energy efficiency, is caused. Due to the fact that in passive optical networks, the available capacity of the feeder fiber is shared among a number of users, the 536 
energy efficiency of GPON and 1G-EPON for up to 1,000 subscribers (Fig. 5d). This is because the data rate per user in PONs is rather limited by the shared transmission media than by the finite uplink capacity of the aggregation switch. A single OLT port is shared among up to 32 users, which leads not only to a reduction of data rate per user but also to a significantly lower total network power consumption. Therefore the most power efficient options when assuming a limited uplink of the central office and a large number of subscribers are passive optical networks. Although the CO uplink limitation affects the energy efficiency of high-speed PONs (10G-EPON) for a large number of subscribers, i.e. for more than 500 subscribers, they remain, however, the most efficient network among the considered options for both limited and unlimited uplink capacity as well as for small and large network sizes.

\section{DISCUSSION}

Environmental implications: Since both average access rate and number of network terminals have been continuously increasing over the last decade, the contribution of the access network infrastructure to the total electricity consumption of the Information and Communication Technology (ICT) sector has been increasing too. High electricity consumption means large energy-related Green House Gas (GHG) emissions. Therefore, it would be of interest to see what impact on GHG emissions access networks already have and how large their impact would be in case of having the same access technology used everywhere.

As a starting point for this case study we take the statistical data for broadband coverage in Europe obtained and published by the IDATE (IDATE Consulting and Research, 2009) and calculate GHG emissions caused by the estimated electricity consumption of access network infrastructure in 27 countries of the European Union (EU) plus Norway and Iceland (EU-27+2). We consider here two hypothetical scenarios. The first scenario bases on the statistical data for the coverage of DSL, HFC and FTTH access technologies in Europe and assumes that all DSL connections are based on VDSL2, HFC uses DOCSIS 3.0 and FTTH is implemented as GPON. The second scenario considers that all subscribers are connected by the same technology, namely either using VDSL2 or HFC DOCSIS 3.0 or GPON. Thus, we are now able to estimate the impact of each considered access technology on GHG emissions. As stated in (IDATE Consulting and Research, 2009), there were in total 115.1 million broadband subscribers within the EU$27+2$ region in 2008 , of which approx. 5.2 milion subscribers used the fixed wireless access. Since we concentrate on a pure wired access, we assume that 110 million subscribers were using a kind of fixed broadband access in 2008. According to reference
(IDATE Consulting and Research, 2009), about 91 million subscribers were connected chiefly by the Digital Subscriber Line (DSL), 17.4 million by the Hybrid Fiber Coax (HFC) and about 1.6 million subscribers used an optical access technology (FTTH). In this study, we assume 10,000 homes per Central Office (CO). The values of energy consumption per bit that we estimated for different access technologies (see the "Results") can be used to calculate the accessrelated GHG emissions. Here, we do not take into account any bandwidth limitation of the uplink. Additionally, we assume that all network equipment is always on. For the calculation of GHG emissions we consider the energy sources mix in Europe that leads to the conversion factor of $0.356 \mathrm{kgCO} 2 \mathrm{e}$ per $\mathrm{kWh}$ (AEA, 2009; Carbon Neutral Company, 2009).

The results regarding GHG emissions caused by the access network infrastructure in the EU for the aforementioned scenarios are shown in Fig. 6-8. The estimated total GHG emissions per year of a Europewide access network are shown in Fig. 6. The first bar on the left-hand side represents the GHG emissions of the first scenario, while the three other bars refer to the hypothetical scenario 2 with only one access technology implemented and used in all 29 European countries. It is evident from the diagram that about $19 \%$ lower GHG emissions would be possible if all subscribers would use VDSL2, while higher emissions could be expected when all 110 million subscribers would be connected by HFC or FTTH. In case of HFC, the total GHG emissions would increase by $99 \%$, while a Europe-wide optical access network based on GPON would generate about $25 \%$ higher emissions.

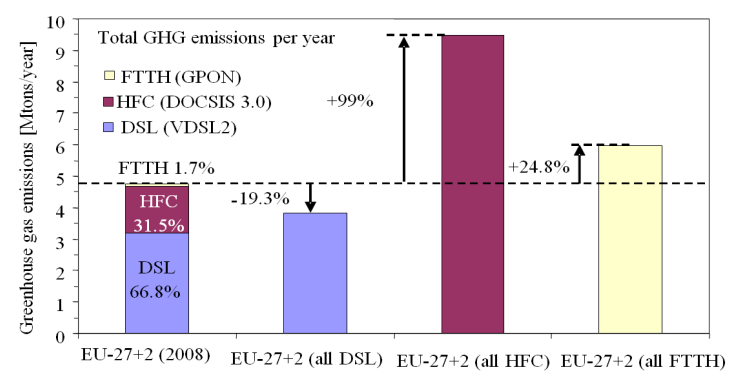

Fig. 6: Calculated total greenhouse gas (GHG) emissions per year of DSL (VDSL2), HFC (DOCSIS 3.0) and FTTH (GPON) networks using the numbers of broadband wired access subscribers in 27 countries of the European Union (EU) plus Norway and Iceland (EU-27+2) at the end of 2008 (IDATE Consulting and Research, 2009). Also shown are GHG emissions of three hypothetical scenarios, in which all subscribers are assumed to use the same technology (DSL, HFC or FTTH) 


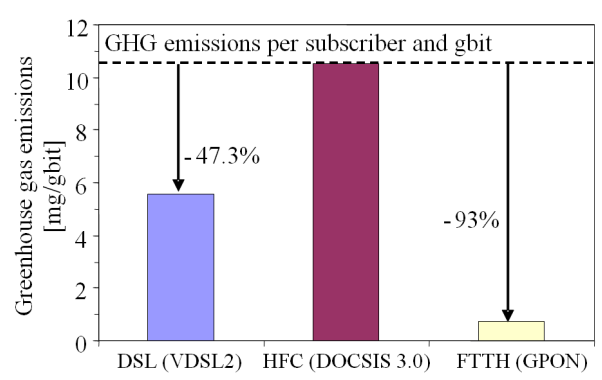

Fig. 7: Greenhouse gas (GHG) emissions per subscriber and Gbit of DSL (VDSL2), HFC (DOCSIS 3.0) and FTTH (GPON) access networks with 10,000 subscribers per CO

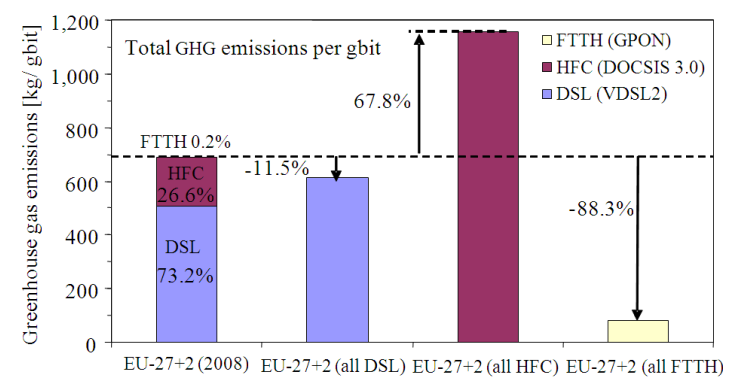

Fig. 8: Calculated total greenhouse gas (GHG) emissions per Gbit of DSL (VDSL2), HFC (DOCSIS 3.0) and FTTH (GPON) networks using the numbers of broadband wired access subscribers in 27 countries of the European Union (EU) plus Norway and Iceland (EU$27+2$ ) at the end of 2008 (IDATE Consulting and Research, 2009). Also shown are GHG emissions of three hypothetical scenarios, in which all subscribers are assumed to use the same technology (DSL, HFC or FTTH)

The amount of Carbon Dioxide equivalent $\left(\mathrm{CO}_{2} \mathrm{e}\right)$ emissions caused by a subscriber for transferring one Gbit of data through either VDSL2, HFC DOCSIS 3.0 or GPON networks is shown in Fig. 7. It can be seen that about $10.5 \mathrm{mg}$ of $\mathrm{CO}_{2} \mathrm{e}$ are produced by $\mathrm{HFC}$ network equipment for transferring one Gbit of data, while a reduced emission per Gbit of up to $47.3 \%$ is possible when using VDSL2 instead of HFC. A large reduction of $93 \%$ can be obtained in a GPON-based network. Hence optical access networks become highly efficient when taking into account the amount of data transferred over time. Therefore, for exchanging a particular amount of data and when assuming switching off network equipment during their inactivity times, optical access networks and in particular passive optical networks such as GPON, have the highest potential to reduce GHG emissions caused by the electricity consumption of the access network infrastructure. One can obtain from Fig. 8 that when looking at the considered network scenarios, a broad use of optical access networks could lead to a reduced GHG emissions per Gbit by approximately $88 \%$.

\section{CONCLUSION}

In conclusions, we evaluated different wired access technologies regarding their energy efficiency. In our study, we considered two scenarios; one with unlimited uplink to the metropolitan area network and another one with an uplink limited to $320 \mathrm{Gbit} / \mathrm{s}$. Our results have shown that for the unlimited case, the high-speed options with $10 \mathrm{Gbit} \mathrm{sec}^{1}$ link data rate show the highest energy efficiency. When the uplink limitation is considered, which can be seen as a realistic assumption for today's networks, passive optical networks become the most power-efficient options. Generally, the FiberTo-the-Node (FTTN) configuration using ADSL2+, VDSL or HFC shows the lowest efficiency, excepting the case in which a large number of subscribers are connected to the central office that has a limited uplink capacity. In this case, VDSL2 in the FTTN arrangement reaches approximately the same energy efficiency as the point-to-point optical Ethernet. Additional to the energy efficiency we also studied the impact of access network infrastructure on the environment through energy-related Greenhouse Gas (GHG) emissions. In our considered hypothetical scenarios, an all-VDSL2 access infrastructure would generate the lowest total GHG emissions when assuming that the network equipment is always in the "on" state. However, for transferring a large amount of data and when network equipment is switched off during its inactivity times, optical access technologies have the highest potential to reduce GHG emissions caused by the electricity consumption of access network infrastructure.

\section{ACKNOWLEDGMENT}

Study described in this study was carried out with the support of the BONE project ("Building the Future Optical Network in Europe"), a Network of Excellence funded by the European Commission through the 7th ICT Framework Programme and the project HOMEICT funded by the Austrian Fund for Climate and Energy and accomplished in the framework of the program "NEUE ENERGIEN 2020". 


\section{REFERENCES}

AEA, 2009. Guidelines to Defra/DECC's GHG Conversion Factors for Company Reporting.

Aleksic S. and A. Lovric, 2010. Power consumption of wired access network technologies. Proceedings of 7th IEEE IET International Symposium on Communication Systems, Networks and Digital Signal Processing (CSNDSP), Jul. 21-23, IEEE Xplore Press, Newcastle upon Tyne, pp: 147-151.

Aleksic, S., 2011. Energy efficiency of electronic and optical network elements. IEEE J. Selected Topics Quantum Elect., 17: 296-308. DOI: 10.1109/JSTQE.2010.2066551

Baliga, J., R. Ayre, W.V. Sorin, K. Hinton and R.S. Tucker, 2008. Energy consumption in access networks. Proceedings of Optical Fiber Communication/National Fiber Optic Engineers Conference, Feb. 24-28, IEEE Xplore Press, San Diego, CA, pp: 1-3. DOI: 10.1109/OFC.2008.4528538

CableLabs, 2007-2010. DOCSIS SpecificationsDOCSIS 3.0 Interface.

Carbon Neutral Company, 2009. Carbon offset factors.

IDATE Consulting and Research, 2009. Broadband Coverage in Europe: Final Report 2009 Survey.

IDATE Consulting and Research, 2009. FTTx 2010, Markets and Trends, Facts and Figures.

IEEE P802.3ah, 2008. "Ethernet in the First Mile Standard.
ITU-T, 2006. Recomendation G.993.2. "Very high speed digital subscriber line transceivers 2 (VDSL2).

ITU-T, 2009. Recommendation, G.992.5. "Asymmetric Digital Subscriber Line (ADSL) transceiversExtended bandwidth ADSL2 (ADSL2+).

ITUT-T, 2008. Recommendation G.984.1: "Gigabitcapable Passive Optical Networks (GPON): General characteristics.

Lam, C.F., 2007. Passive Optical Networks. 1st Edn. Principles and Practice. Elsevier Inc., Academic Press, pp: 368.

Large, D. and J. Farmer, 2009. Broadband Cable Access Networks. 3rd Edn., The HFC Plant, Elsevier Inc., Morgan Kaufmann, pp: 432.

Lovric, A. and S. Aleksic, 2010. Power Efficiency of Extended Reach 10G-EPON and TDM/WDM PON. Proceedings of the National Fiber Optic Engineers Conference (NFOEC), Mar. 21, Optics Info Base, San Diego, California.

RVA Market Research and Consulting, 2011. North American FTTH Status, March 2011, FTTH Council, 2011, RVA, Tulsa, OK, pp: 1-5,

Starr, T., M. Sorbara, J.M. Cioffi and P.J. Silverman, 2003. DSL Advances. 1st Edn. Prentice Hall Technical Reference Book, pp: 576.

Suzuki, K.I., 2008. Long reach PON system using optical fiber amplifier. Proceedings of the OFC/NFOEC Workshop, (OFC/NFOEC' 08), OSuF, San Diego, CA, USA. 